\title{
The Application of Corrective Underwater Spinal Traction with Underwater Phototherapy to the Spine Pathology
}

\author{
Bitsoev Vladimir Dodtievich \\ Physiotherapy Department, Frumkin Research Institute of Physical Chemistry, Moscow, Russia
}

Email address:

bitsoev@mail.ru

\section{To cite this article:}

Bitsoev Vladimir Dodtievich. The Application of Corrective Underwater Spinal Traction with Underwater Phototherapy to the Spine Pathology. Clinical Medicine Research. Vol. 4, No. 6, 2015, pp. 204-213. doi: 10.11648/j.cmr.20150406.17

\begin{abstract}
In this work, we study the effect of water structure on absorption spectra of water that is subject to electromagnetic radiation of the following types: 1. polychromatic visible and infrared polarized (PVIP) light emitted by a "Bioptron" device with a wavelength of 480 to $3,400 \mathrm{~nm}$ and frequency of 625 to $88 \mathrm{THz}$ under water via a fiber optic cable and with an exposure of 2, 4, 6, 10, 15, and 30 minutes; 2. electromagnetic waves belonging to a $5.6 \mathrm{~mm}$ range with a frequency of 50-52 GHz and an exposure of 2, 4, 6, 10, 15, and 30 minutes via a radiation source with dimensions over $5 \mathrm{~cm}$ immersed into water; 3. one-time effect of PVIP light and $\mathrm{CO}_{2}$ at a temperature of $0^{\circ} \mathrm{C}$ and with an exposure of 4 minutes; 4 . one-time effect of electromagnetic waves belonging to a $5.6 \mathrm{~mm}$ range and $\mathrm{CO}_{2}$ at a temperature of $0^{\circ} \mathrm{C}$ and with an exposure of 4 minutes; 5. effect of PVIP light on water from a $10 \mathrm{~cm}$ height above the water surface. The conducted studies have shown that the best changes occur in water irradiated with PVIP light during 4 and 15 minutes as compared to the absorption spectra of a control specimen of tap water. Significant changes in the water structure occurred if water was irradiated with PVIP light from a 10-cm height above the water surface during 15 minutes. The studies showed as well that after the end of 4- and 15minute exposure of water to electromagnetic waves (26 and 15 minutes later, respectively) the water structure significantly improved owing to its unique ability to store and transmit information.
\end{abstract}

Keywords: Structure Water, Spectroscopy, Information

\section{Introduction}

A combination of phototherapy (Bioptron) with underwater spinal traction is a general conservative treatment method of degenerative-dystrophic processes developing in anatomic structures of the spine and frequently attended by the pain syndrome.

This technology promotes "relief" of intervertebral discs, increases diastasis of articular surfaces of intervertebral joints, and has a positive effect on spastic muscles inducing their relaxation.

It should be emphasized that strong anti-inflammatory and immunomodulatory effects of polychromatic visible and infrared polarized (VIP) light from Bioptron have been proved by the fundamental international and Russian research (Doctor of Biology, Professor K.A. Samoilova Institute of Cytology, Russian Academy of Sciences, SaintPetersburg, 2003; Doctor of Medicine, PhD M.P. Kataeva SOGMA, Vladikavkaz, 2000; Professor L. Medenitsa Institute of Dermatology and Venerology, Clinical Center of
Belgrade University, Serbia, Yugoslavia, 2003; Professor M. Lenz - University of Oxford, Great Britain) [6, 8, 9, 11, 15].

"VIP light phototherapy leads to a rapid six-fold increase of interferon- $\gamma$ (IFN- $\gamma$ ), the key immunomodulator in blood, even its initial level being normal. The cell immune response activation (the functional state of monocytes, macrophages, natural killers and cytotoxic T-lymphocytes) is the key function of this cytokine that increases antiviral and antitumor resistance of the organism" (Prof. K.A. Samoilova, 2003) $[11,15]$.

It has been already found that nitrogen oxide (NO) formation in the systemic circulation is the primary mechanism for visible and IR light effects which are: widening of blood vessels (vasodilation) and platelet disaggregation, without them phototherapy would hardly be highly efficient.

Currently there is ongoing research of processes proceeding in water and aqueous solutions exposed to electromagnetic fields $[5,10,12,13]$.

Water is known for its ability to copy and record information. 
As known from the studies by N.I. Sinitsin et al. (1998), human tissues and water have identical resonance frequencies. This similarity of resonance EHF spectra of human media and water indicates the same physical nature of millimeter-wave interaction with the molecular structure of water in both these objects $[1,12]$.

\section{Methods and Base of Research}

The first part of the research concerns the study of light absorption in water after EMR source action:

1. Polychromatic visible and infrared polarized (VIP) light with 480-3400 nm wavelengths and $625 \mathrm{THz}-88$ $\mathrm{THz}$ respective frequencies from Bioptron, under water via a fiber optic cable, with 2, 4, 6, 10, 20 and 30 minute exposure;

2. Electromagnetic waves of $5.6 \mathrm{~mm}$ range, $50-52 \mathrm{GHz}$ frequency, 2, 4, 6, 10, 15 and 30 minute exposure to submerged radiation source greater than $5 \mathrm{~cm}$ in size;

3. 4 minute exposure of water to polychromatic VIP light and $\mathrm{CO}_{2}$ at $0^{\circ} \mathrm{C}$, simultaneously;

4. 4 minute exposure of water to $5.6 \mathrm{~mm}$ electromagnetic waves and $\mathrm{CO}_{2}$ at $0^{\circ} \mathrm{C}$ temperature, simultaneously;

5. 15 minute exposure of water to polychromatic VIP light from $10 \mathrm{~cm}$ above surface.

Frumkin Research Institute of Physical Chemistry (Moscow) has carried out a research where water was exposed to polychromatic VIP light. Its effect was studied using IRspectroscopy in the range of 4000-400 $\mathrm{cm}^{-1}$ using Perkin-Elmir 2000 Fourier spectrometer. Wave Research Center of Prokhorov General Physics Institute RAS (Moscow) carried out similar research using spontaneous Raman scattering method under the action of $532 \mathrm{~nm}$ laser radiation.

\section{The Results of Researches}

The study found that, as compared with the absorption spectrum of tap water control sample, the best changes in water occur: after 4 minute irradiation by polychromatic VIP light underwater via a fiber optic cable (Fig. 1, curves 1 and 3 , respectively); after 15 minute irradiation by polychromatic VIP light from the height of $10 \mathrm{~cm}$ above water (Fig. 1, curve 7). The most significant changes in water occur after 4 minute irradiation by polychromatic VIP light underwater via a fiber optic cable with simultaneous saturation by $\mathrm{CO}_{2}$ cooled down to $0^{\circ} \mathrm{C}$ (Fig. 1, curve 4 ).

Curves:

1. - initial sample (tap water);

2. -2 minute irradiation;

3. -4 minute irradiation;

4. -4 minute irradiation with simultaneous saturation by $\mathrm{CO}_{2}$ cooled down to $0^{\circ} \mathrm{C}$;

5. -6 minute irradiation;

6. -10 minute irradiation;

7. -15 minute irradiation by Bioptron located $10 \mathrm{~cm}$ above water;

8. -20 minute irradiation;

\section{9. -30 minute irradiation.}

When water is exposed to 2, 6, 10, 20 and 30 minute irradiation via fiber optic cable underwater, no absorption is observed (Fig. 1, curves 2, 5, 6, 8 and 9, respectively; curve 1 - control sample).

The data on spectral analysis of water irradiated by 5.6 $\mathrm{mm}$ electromagnetic waves with the frequency of $50-52 \mathrm{GHz}$ (Fig. 2) are virtually identical to these of water exposed to polychromatic VIP light with $480-3400 \mathrm{~nm}$ wavelengths and of $625 \mathrm{THz}-88 \mathrm{THz}$ respective frequencies, i.e. the best changes also occur after 4 and 15 minute irradiation (Fig. 2, curves 3 and 7 , respectively). At the same time, note that 2 , 6,10 and 30 minute irradiation of water by $5.6 \mathrm{~mm}, 50-52$ $\mathrm{GHz}$ electromagnetic waves and 4 minute irradiation of water with its simultaneous saturation by $\mathrm{CO}_{2}$ at $0^{\circ} \mathrm{C}$ give no significant changes.

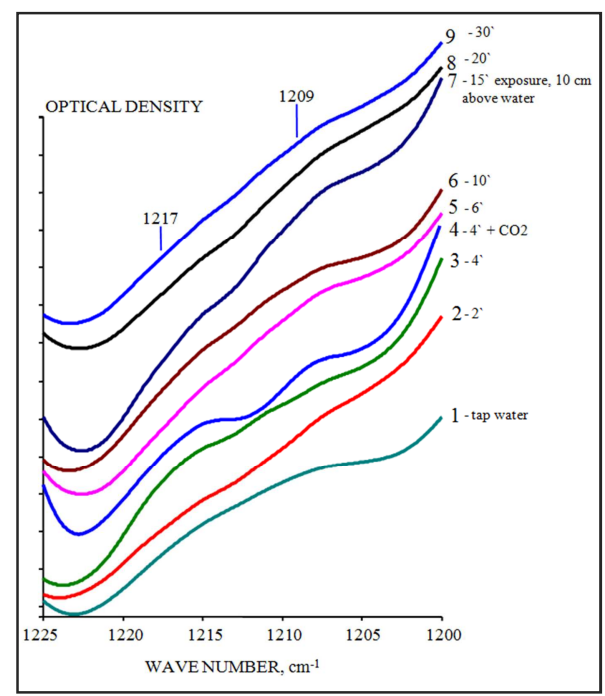

Fig. 1. IR-spectra of water after exposure to polychromatic VIP light of 480$3400 \mathrm{~nm}$ wavelengths and $625 \mathrm{THz}-88 \mathrm{THz}$ respective frequencies from Bioptron.

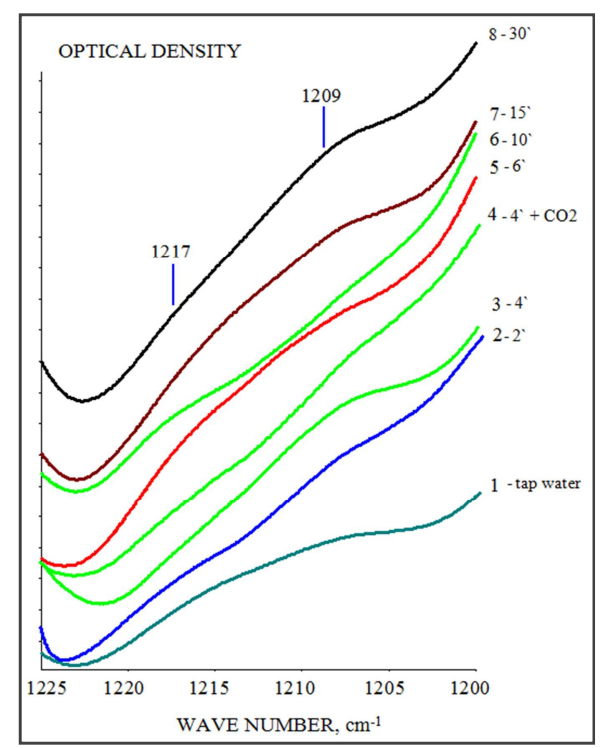

Fig. 2. IR-spectra of water exposed to $5.6 \mathrm{~mm} \mathrm{EMR} \mathrm{of} \mathrm{50-70} \mathrm{GHz}$ frequency (EHF radiation). 
Curves:

1. - Initial sample (tap water);

2. -2 minute irradiation;

3. -4 minute irradiation;

4. -4 minute irradiation with simultaneous saturation by $\mathrm{CO}_{2}$ cooled down to $0^{\circ} \mathrm{C}$

5. -6 minute irradiation;

6. -10 minute irradiation;

7. -15 minute irradiation by Bioptron located $10 \mathrm{~cm}$ above water;

8. -30 minute irradiation.

To further examine the light absorption properties of water, after 4 and 15 minute polychromatic VIP light irradiation by Bioptron device (Fig. 3, curves 1 and 3, respectively), the source of electromagnetic waves was switched off, and 26 and 15 minutes after, i.e. 30 minutes after the irradiation of water started, a significant increase of light absorption was detected using the IR-spectroscopy (Fig. 3, curves 2 and 4, respectively).

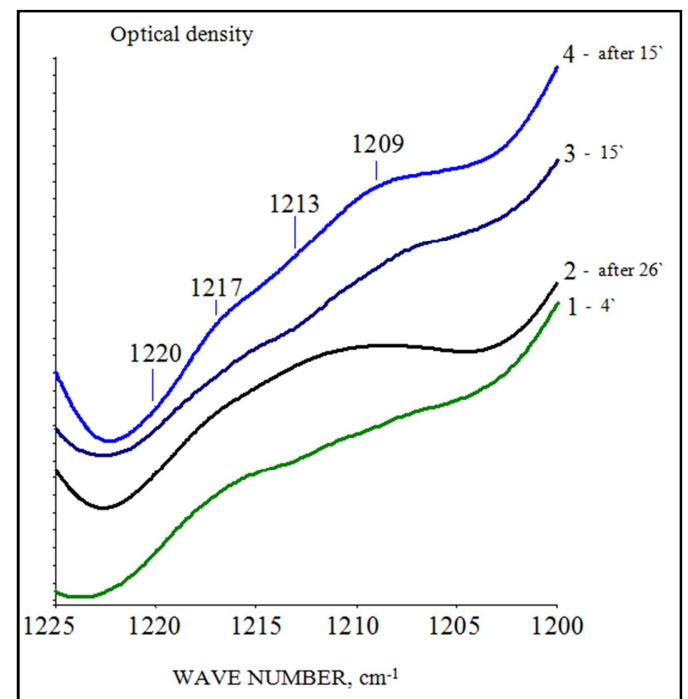

Fig. 3. IR-spectra of water after exposure to polychromatic VIP light from Bioptron device.

Curves:

1. -4 minute irradiation;

2. -26 minutes after the 4 minute irradiation;

3. -15 minute irradiation;

4. -15 minutes after the 15 minute irradiation.

On this issue, an experiment was set up (Fig. 4), in which blood plasma of a volunteer M., 39 years old, was studied using IR spectroscopy method: Fig. 4, curve 1 - a spectrum of plasma not exposed to EMR (control); curve 2 - a spectrum of plasma after 4 minute irradiation by electromagnetic fields from Bioptron device in a Petri dish; curve 3 - a spectrum of plasma after 15 minute irradiation by polychromatic VIP light from Bioptron device in a Petri dish; curve 4 - a spectrum of patient's plasma 60 minutes after 15 minute bathing in water preliminarily exposed to Bioptron polychromatic VIP light during 15 minutes.

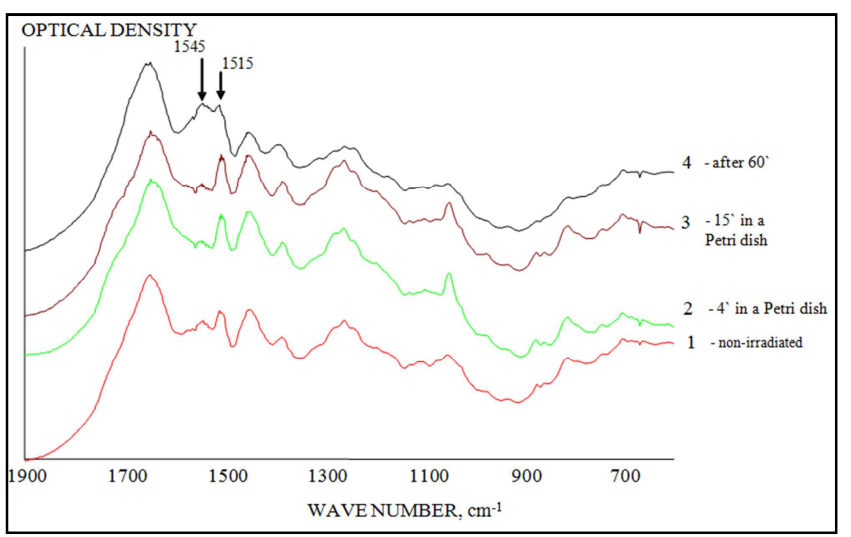

Fig. 4. IR-spectra of blood plasma after exposure to polychromatic VIP light from Bioptron device.

Curves:

1. - spectra of non-irradiated plasma (control);

2. - a spectrum of plasma after 4 minute exposure to polychromatic VIP light in a Petri dish;

3. - a spectrum of plasma after 15 minute exposure to polychromatic VIP light in a Petri dish;

4. - a spectrum of plasma 60 minutes after the 15 minute bathing in water preliminarily exposed to Bioptron polychromatic VIP light during 15 minutes.

The results of this experiment show that the blood plasma absorbs light (Fig. 4, curves 2, 3 and 4, as compared with the control), as water does, but also indicate a significant light absorption increase in it an hour after 15 minute bathing in water preliminarily exposed to Bioptron polychromatic VIP light during 15 minutes. Consequently, there is reason to believe that further investigation of this problem (the phenomenon of electromagnetic wave interaction with water) is of special interest.

The spectral pattern of curves in Figs. 1-3 at fixed time irradiation of water demonstrates pronounced absorption bands at 1217 and $1209 \mathrm{~cm}^{-1}$. For the blood plasma irradiation in vivo and in vitro, Fig. 4 shows absorption bands at 1545 and $1515 \mathrm{~cm}^{-1}$.

Many immunomodulatory, anti-inflammatory and antiviral drugs are known to have electromagnetic absorption bands at $1217,1209,1544$ and $1515 \mathrm{~cm}^{-1}[4,5]$.

Such a coincidence with the results of this research needs further study according to a separate program. Prokhorov Institute of General Physics RAS took on with the investigation of polychromatic VIP light.

It is known that the reason for Raman scattering is association of electron motion with the nuclear one.

Mutual arrangement of the nuclei defines a field, where the electron cloud locates.

The ability of electromagnetic cloud to be deformed due to the effect of electric field of an electromagnetic wave depends upon configuration of nuclei at a particular moment and, in case of intramolecular vibrations, varies with their frequency. And vice versa, when the electron cloud deforms, vibrations of the nuclear framework of the molecule may occur [14]. 
The combined scattering itself may be represented as a "reaction" of the photon interaction with a molecule:

$\gamma+\mathrm{A} \rightarrow \gamma^{\prime}+\mathrm{A}$

where the internal energy of the molecule increases $\left(\mathrm{Ea} \rightarrow \mathrm{Ea}^{\prime}=\mathrm{Ea}+\Delta \mathrm{E}\right)$, and the photon energy decreases ( $\hbar \mathrm{w}$ $\left.\rightarrow \hbar \mathrm{w}^{`}+\Delta \mathrm{E}\right)$ accordingly. A process $\left(\gamma+\mathrm{A}^{\prime} \rightarrow \gamma+\mathrm{A}\right)$ is also possible, in which an excited molecule transits to a lower energy state, whereas the photon energy increases: $\hbar \mathrm{w}+\mathrm{E}^{`}=\hbar \mathrm{w}^{`}+\mathrm{E}$, i.e. along with the fundamental radiation frequency, the spectrum of scattered light obtains new components. These very new frequencies in the scattering spectrum (which depend upon the molecular structure) are called the Raman spectrum.

In this case, the internal state of the molecule changes. The molecule transits from one energy state $\mathrm{E}$ (described by quantum numbers $\mathrm{n}, \mathrm{v}$ and $\mathrm{j}$ - electronic, vibrational and rotational (angular momentum), respectively) to other ones, E'.

In the standard experimental setup for the Raman scattering observation, the test substance is irradiated by a frequency, at which it does not absorb, i.e. the photon is not large enough to translate molecules into the excited electronic state. However, interaction of this quantum induces an agitation of the molecular shell, which rearranges itself thus changing vibrational state of the nuclear skeleton. Meanwhile, the molecule transits to a new vibrational state, $v^{\prime}$, located above (e.g. from $v=0$ to $v^{`}=1$ ) or beneath (e.g. from $v=1$ to $v^{`}=0$ ) the initial state, $v$.

The Raman scattering is incoherent, because different molecules have independent vibration phases [2, 3].

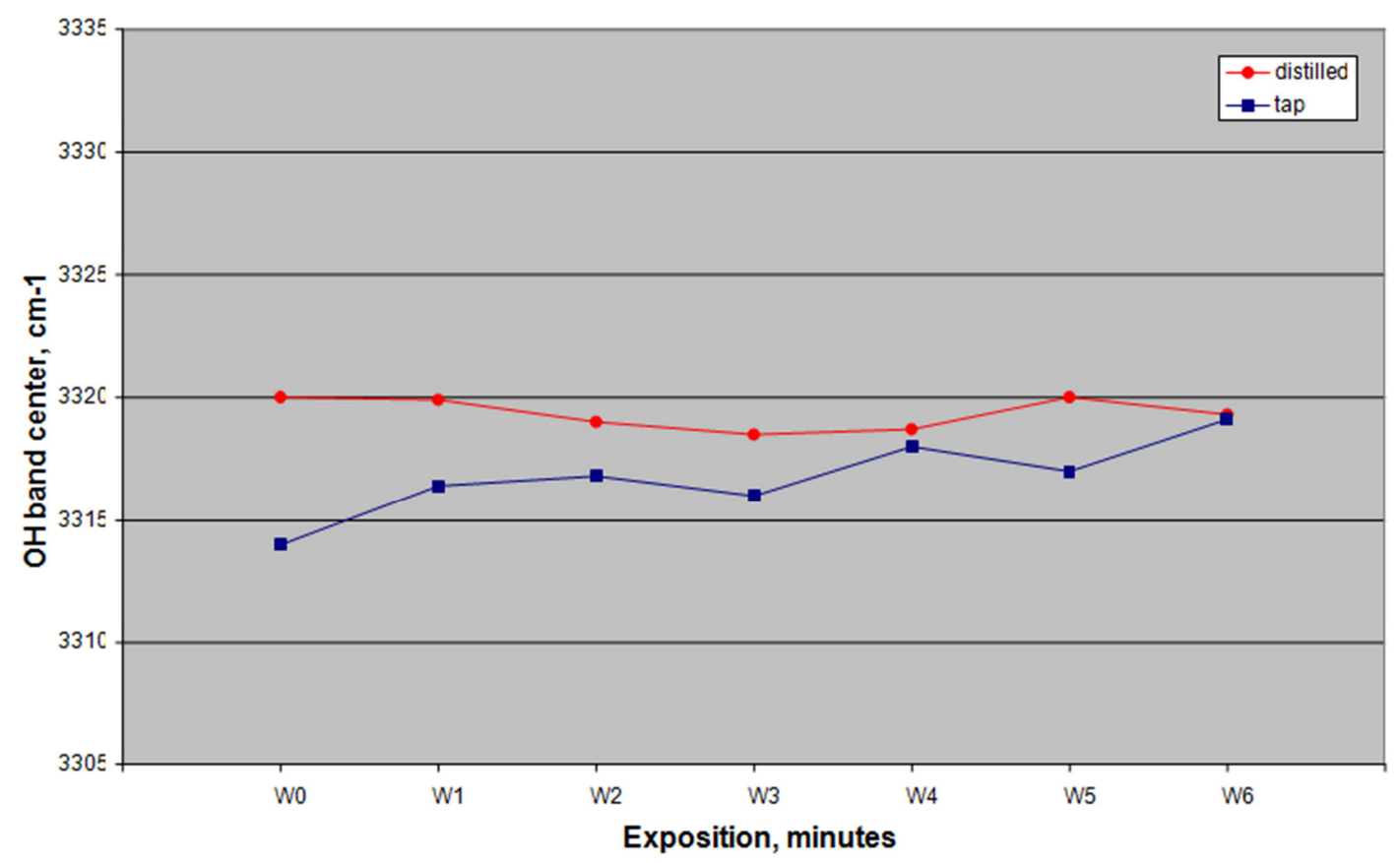

Fig. 5. OH center positions for water samples (double-distilled water and tap water).

An experiment with the Raman spectroscopy of two water samples: 1) double-distilled water and 2) tap water, after irradiation by polychromatic VIP light was set up (Fig. 5), in which the position of $\mathrm{OH}$ stretching vibration band center was measured.

Several series of measurements of 1000 pulses each at different exposures with the frequency of $5 \mathrm{~Hz}$ were performed. To calculate the weighted center of the spectrum taken for some characteristic value, $\mathrm{OH}$ band spectra were processed by the Gaussian weighting function.

For the first sample (double-distilled water), 7 measurements were performed: before irradiation and after irradiation that lasted $1,2,3,4,5$ and 6 minutes. Corresponding points on the Figure are denoted as W0, W1, W2, W3, W4, W5 and W6 (Fig. 5; is distilled water).

For the second sample (tap water), more 7 measurements were performed: before irradiation and after irradiation that lasted 1, 2, 3, 4, 5 and 6 minutes (see Fig. 5). The graph shows polychromatic VIP light effects on water. Water is activated.

Water $\mathrm{pH}$ variations were also determined. In the first sample (double-distilled water), prior to irradiation $\mathrm{pH} 7.0$ was observed; after 4 minute irradiation, $\mathrm{pH} 6.5$ was measured.

For the second sample (tap water), $\mathrm{pH}$ values are: 6.5 prior to irradiation and 6.0 after 4 minute irradiation.

For the control, lemon juice and acetic acid $\mathrm{pH}$ were measured. As observed, prior to irradiation, lemon juice had $\mathrm{pH}$ 7.0, and after 4 minute irradiation - 5.0. Acetic acid had $\mathrm{pH} 5.0$ prior to irradiation and $\mathrm{pH} 5.0$ after 4 minute irradiation. It was also found in the experiment that $\mathrm{pH}$ tended to decrease with water temperature, as well as to increase with it.

Water $\mathrm{pH}$ was studied on the basis of Laboratory of Sanitary-Epidemiological Station, Eastern District of Moscow. 


\section{Results of Efficiency of Treatment of Patients with Backbone Pathology}

Based on the above, for the first time, we applied underwater phototherapy combined with underwater spinal traction (Fig. 6,7).

The technical result of the proposed method is the maximal therapeutic effect due to provision of a single-shot light impact on the whole skin area of a man under the water (Fig. 6).

At the early stage of bone change development, the metered dose traction promotes an increase of diastasis of spurs and pain relief.

The loading is smooth, accurately controlled and monitored, and provides the maximum therapeutic effect, as well as eliminates the possibility of excessive loads. Traction is smooth, giving the patient an opportunity to adapt to the stress load, and is quantity and time controllable (Fig. 7).

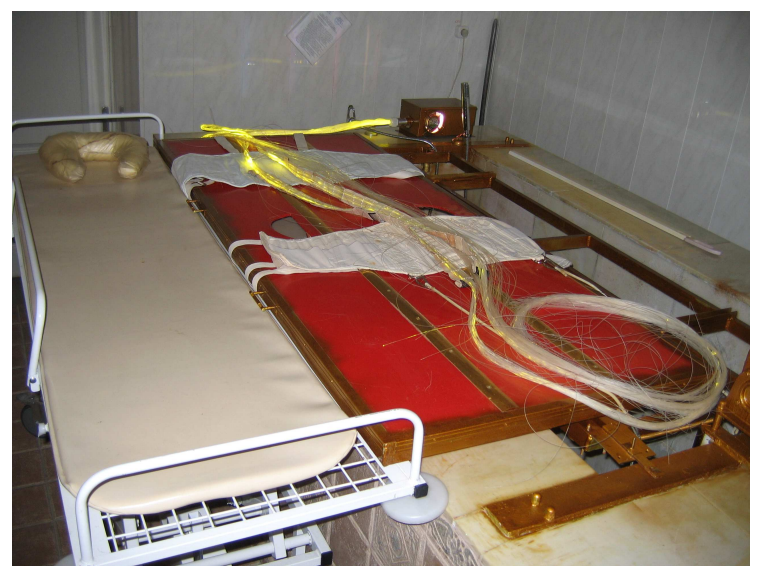

Fig. 6. A unit for underwater phototherapy.

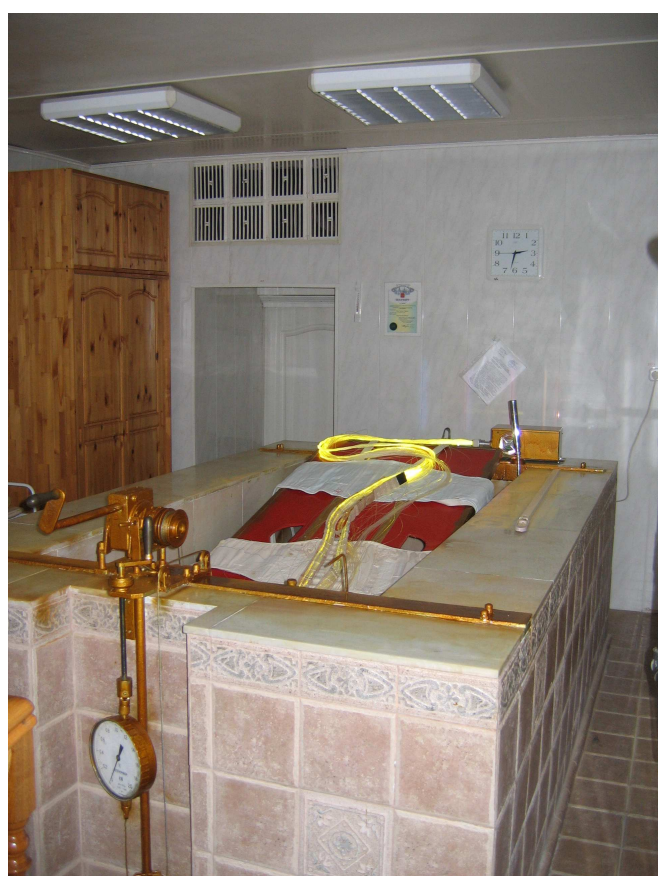

Fig. 7. Fiber optic cable application to under water phototherapy.

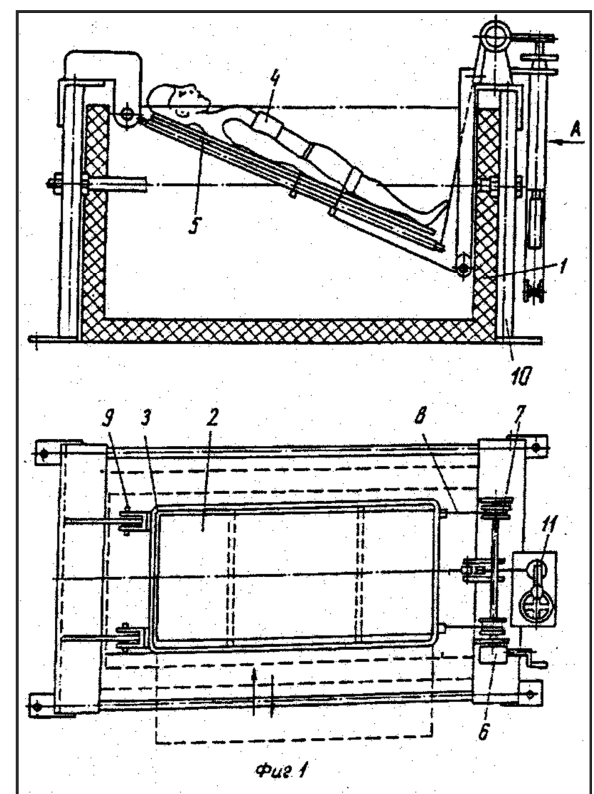

Fig. 8. A unit for underwater spinal traction

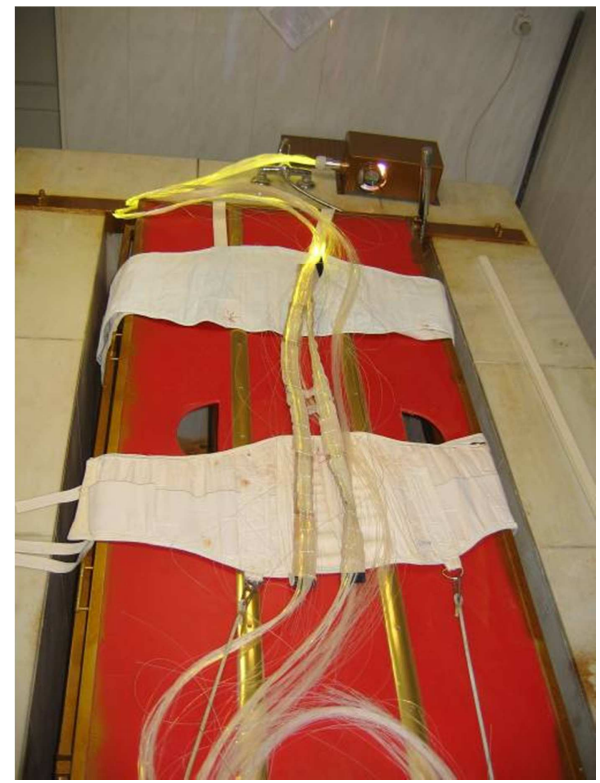

Fig. 9. A unit for underwater spinal traction with underwater phototherapy.

The second part of the research is devoted to evaluation of the treatment efficiency, performed in 2003-2008 by City Policlinic No. 69, Eastern District of Moscow, participants: 745 patients aged from 17 to 60 , with the spine pathology (Fig. 10).

All patients were split into five groups:

i. Patients treated with medication - 175 people;

ii. Patients treated with medication and physiotherapy 157 people;

iii.Patients treated with physiotherapy and underwater phototherapy - 153 people;

iv.Patients treated with physiotherapy and underwater spinal traction - 132 people;

v. Patients treated with underwater spinal traction and underwater phototherapy - 128 people. 


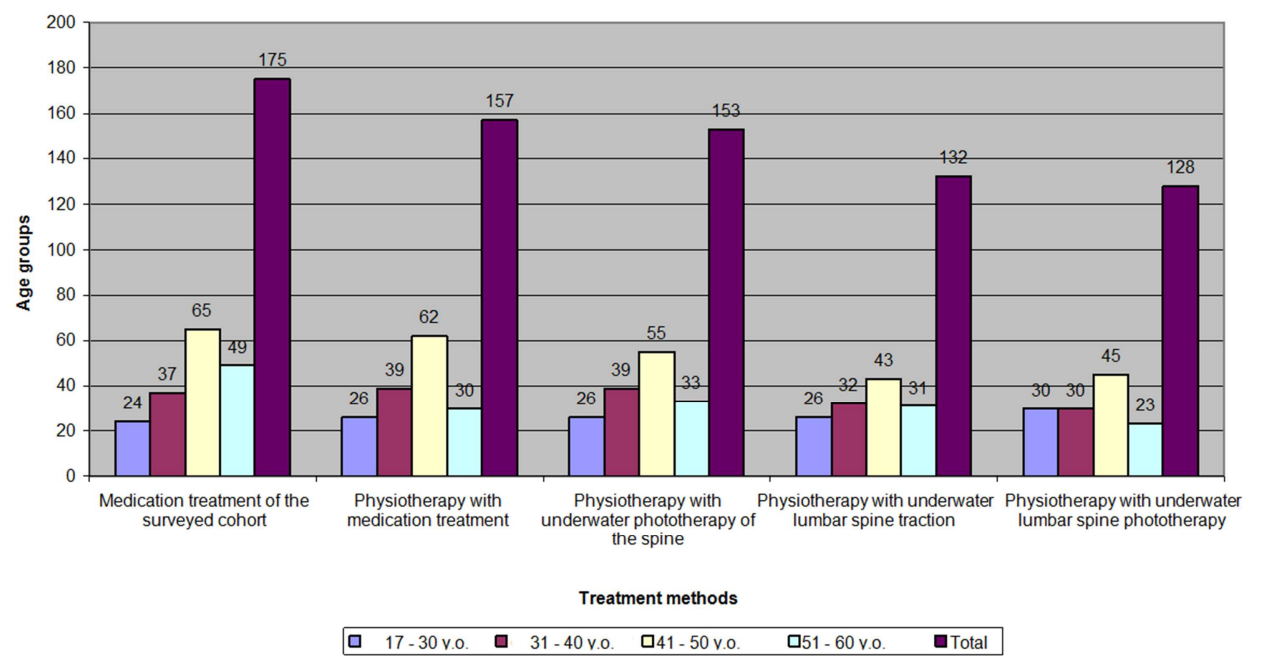

Fig. 10. Surveyed cohort distribution with osteochondrosis of the lumbosacral spine by treatment methods and age groups ( $n=745)$.

By age, the patients were split into 4 groups (Fig. 11):

1) 17 - 30 years old (y.o.) (18\%);

2) 31 - 40 years old $(24 \%)$;

3) 41 - 50 years old $(36 \%)$;

4) 51 - 60 years old $(22 \%)$.

The third group supersedes the rest age groups $-36 \%$; the second group gives $24 \%$; and the first age group is the smallest $-18 \%$.

In all four groups men dominated (Fig. 12). Taking into account single observations of the patients with hernias of the upper lumbar discs, thoracic spine and all lumbar discs, the patients with $\mathrm{L}_{4}-\mathrm{L}_{5}$ and $\mathrm{L}_{5}-\mathrm{S}_{1}$ disc hernias, 40.7 and $30.8 \%$, respectively, were included in the investigation (Fig. 13).

Fig. 14 shows the distribution curve of patients with osteochondrosis of the lumbosacral spine with $5-13 \mathrm{~mm}$ hernia protrusion into the spinal canal and up to $5 \mathrm{~mm}$ protrusion. All patients are distributed by 9 clinical signs (Fig. 15):

1. Lumbodynia;

2. Radiculopathy;

3. Pain caused by axial load on the spine;

4. Restrictions of spinal motions;

5. Erect lordosis with the back muscle strain;
6. Scoliosis, kyphosis, kyphoscoliosis;

7. Root stretch symptoms;

8. Reduction or loss of T-reflexes in pelvic limbs;

9. Sensitivity violation in the spinal nerve innervations zone.

The following clinical signs dominated in the groups (Fig. 15): group $1-1,9,6,4,2,8,3$; group $2-3,7,1,2,9,4,5$; group $3-1,3,5,6,9,2,7$; group $4-1,2,4,3,5,6,9$; group $5-1,3,5,2,4,9,7$.

Fig. 16 presents the results on treatment efficiency for all patients of these five groups:

Regression (the absence of the pain syndrome with persistent remission): group $5-95 \%$; group $4-86 \%$; group $3-79 \%$; group $2-56 \%$; and group $1-52 \%$;

Unchanged (no clinical dynamics): group $1-35 \%$; group $2-29 \%$; group $4-14 \%$; and group $5-5 \%$, the lowest;

Aggravation (negative clinical dynamics): group $2-15 \%$ and group $1-13 \%$. In groups 3, 4 and 5, no aggravation was observed.

The treatment efficiency results are statistically confident with $\mathrm{p}<0.05$.

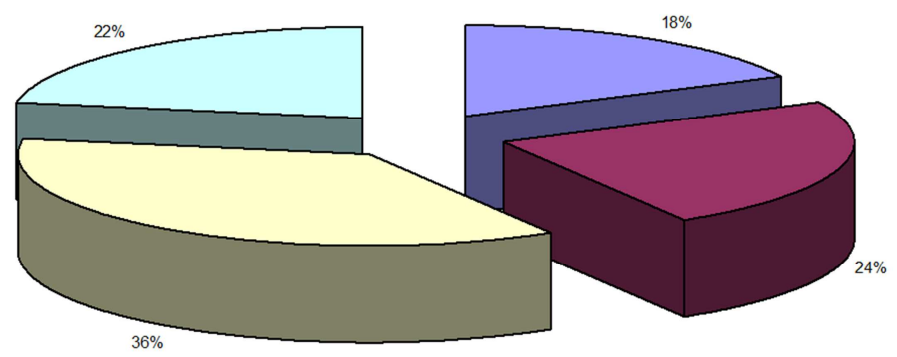

$\square 17-30$ y.0. $\square 31-40$ y.0. $\square .41-50$ y.0. $\square 51-60$ y.०.




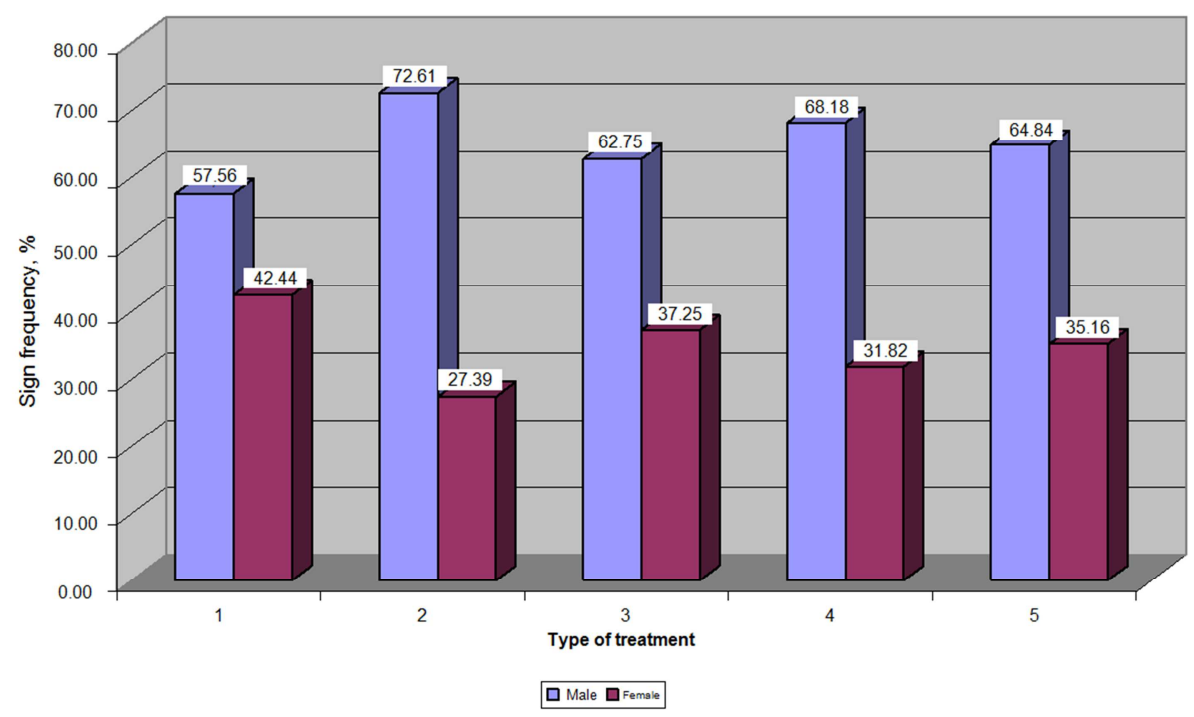

Fig. 12. Distribution of patients by gender.

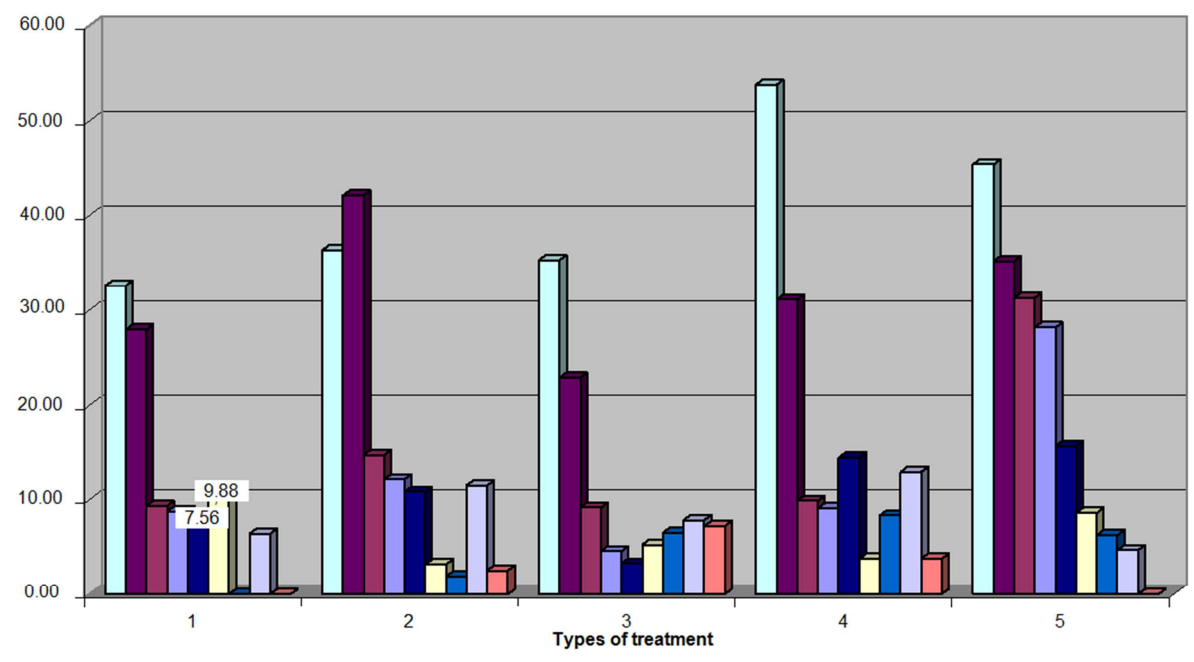

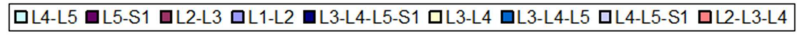

Fig. 13. Distribution of patients by localization of hernias $(n=745)$.

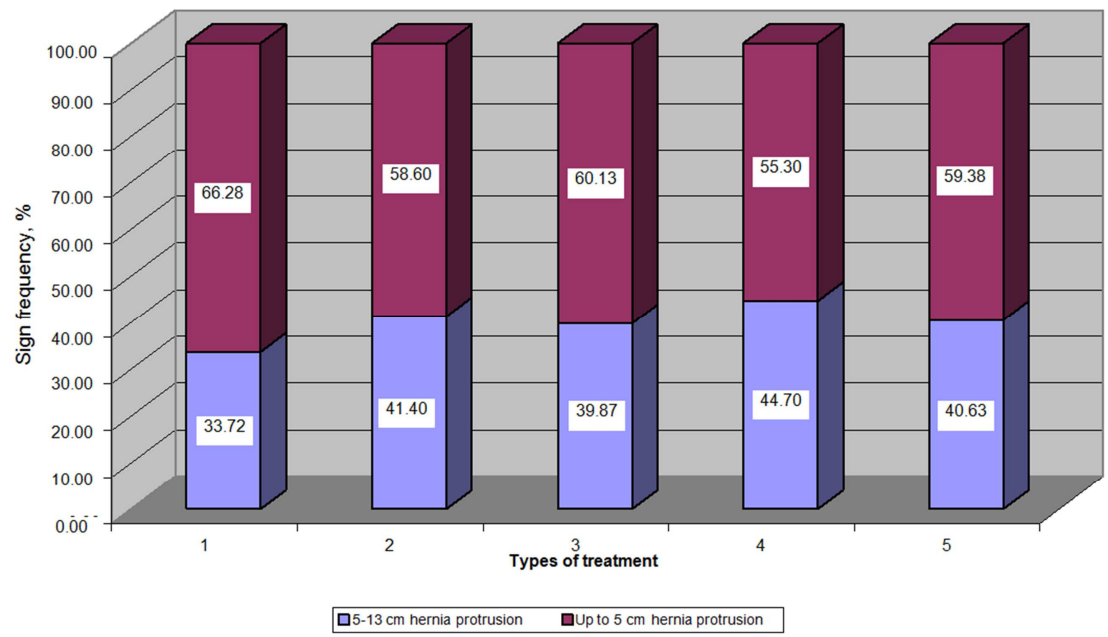

Fig. 14. Distribution of the patients with osteochondrosis of the lumbosacral spine. 


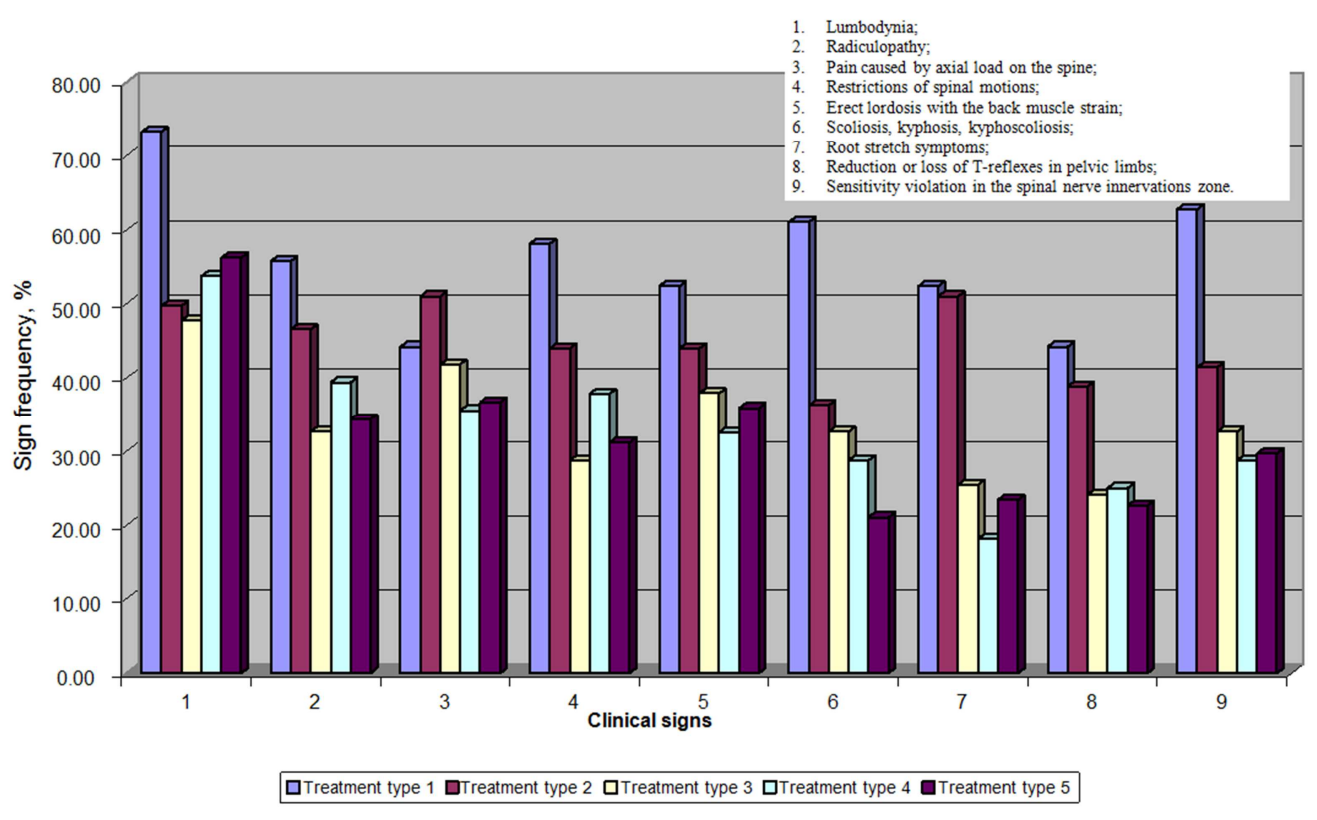

Fig. 15. Distribution of patients by clinical signs $(n=745)$.

Comparison of the efficiency results for 5 types of treatment.

The efficiency of five implemented types of treatment was evaluated by comparing the following 8 criteria: 1-Regression - pain syndrome is absent.

2-Regression - persistent remission.

3-Unchanged - the absence of clinical dynamics.

4-Unchanged - transfer to hospital treatment.

5-Unchanged - outpatient treatment expansion.

6-Aggravation - negative clinical dynamics.

7-Aggravation - transfer to hospital treatment.

8-Aggravation - outpatient treatment expansion.

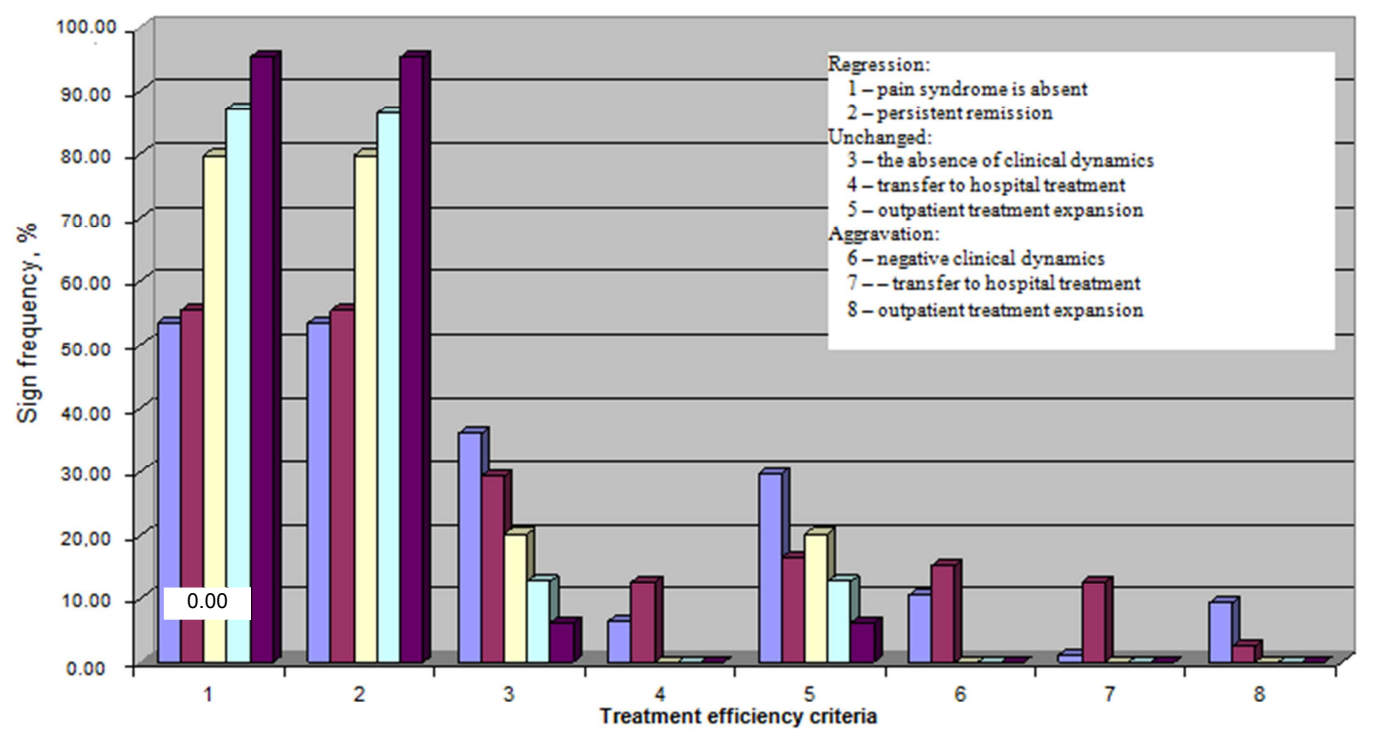

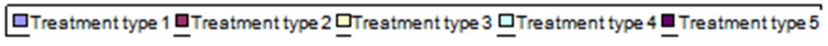

Fig. 16. Efficiency evaluation for 5 types of treatment.

Among types of treatment under consideration, the highest sign frequency (regression - pain syndrome is absent) is provided by type 5 ; differences between this sign frequency and frequencies of other types of treatment is statistically 
confident.

The maximum sign frequency (regression - persistent remission) is observed for treatment types 3 and 4 (Fig. 15).

Types 3 and 4 allow clinical regression - persistent remission, of the same reliability, whereas the rest types (currently 1 and 2) are much less effective (with statistically confident differences).

In witness whereof, the results of MRI of the patient Melamed S.P. before treatment, held on June 05, 2006 should be presented: the rear central-right-sided guttate hernia of $\mathrm{L}_{4-}$ $\mathrm{L}_{5}$ disc sized $9 \times 13 \mathrm{~mm}$, with narrowing of redicular holes mostly at the right, pronounced deformation of the dural sac and affection of the "horse tail" elements is observed. The rear central-left-sided hernia of $\mathrm{L}_{5}-\mathrm{S}_{1}$ disc sized $7.5 \mathrm{~mm}$, with narrowing of redicular holes and dural sac deformation is also observed.

The MRI results after the treatment on December 18, 2006 indicate the rear $\mathrm{L}_{4}-\mathrm{L}_{5}$ disc hernia on a broad base sized 6.5 $\mathrm{mm}$, with moderate narrowing of redicular holes and dural sac deformation.

The height and structure of vertebral bodies weren't changed.

Conclusion: as compared with the survey on June 05, 2006, clear positive dynamics is observed.

The patient refused the operative treatment.

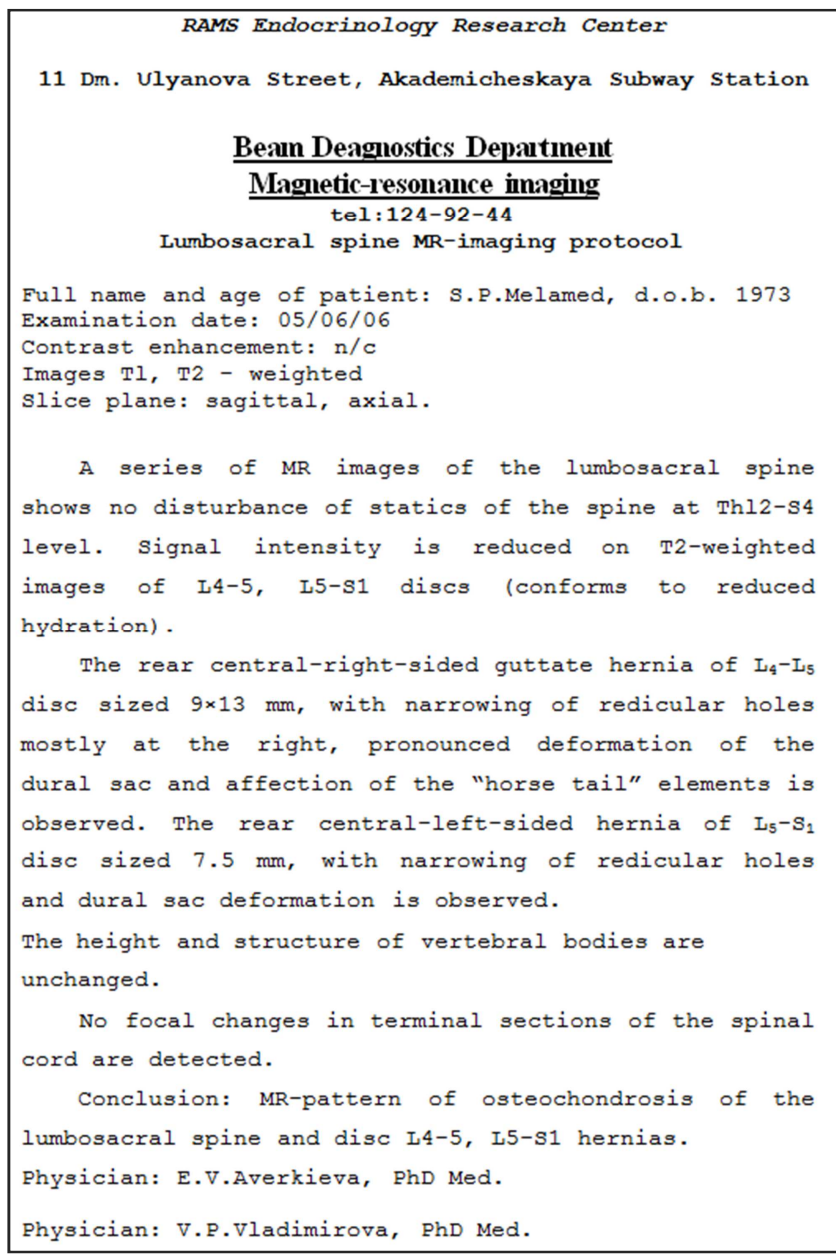

Fig. 17. Magnetic-resonance imaging before starting the treatment.

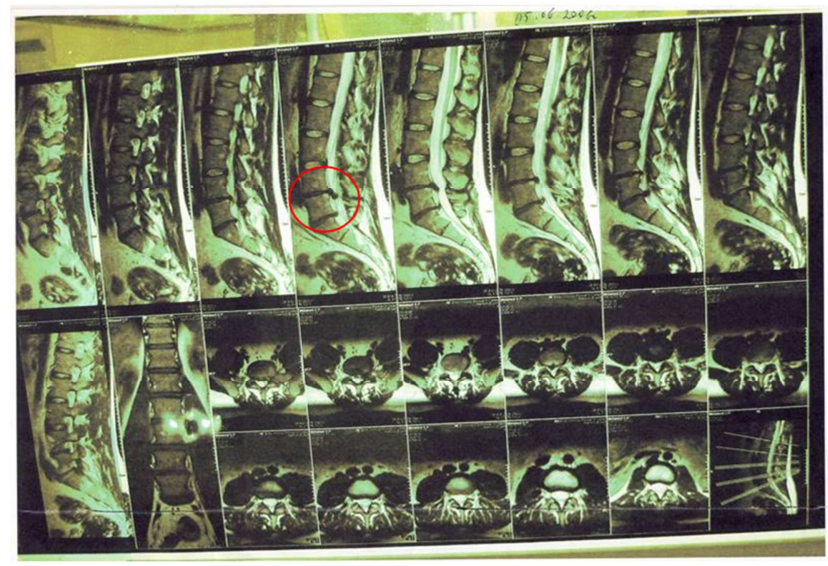

Fig. 18. Magnetic and resonant imaging of lumbosacral spine before starting the treatment.

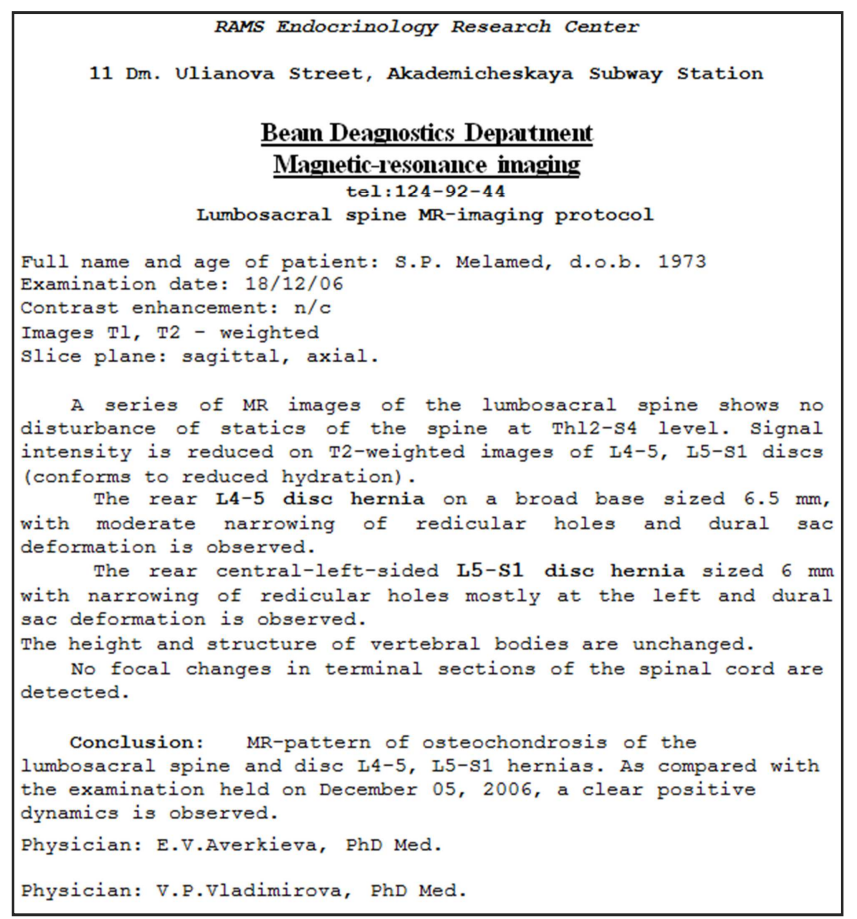

Fig. 19. Magnetic-resonance imaging after starting the treatment.

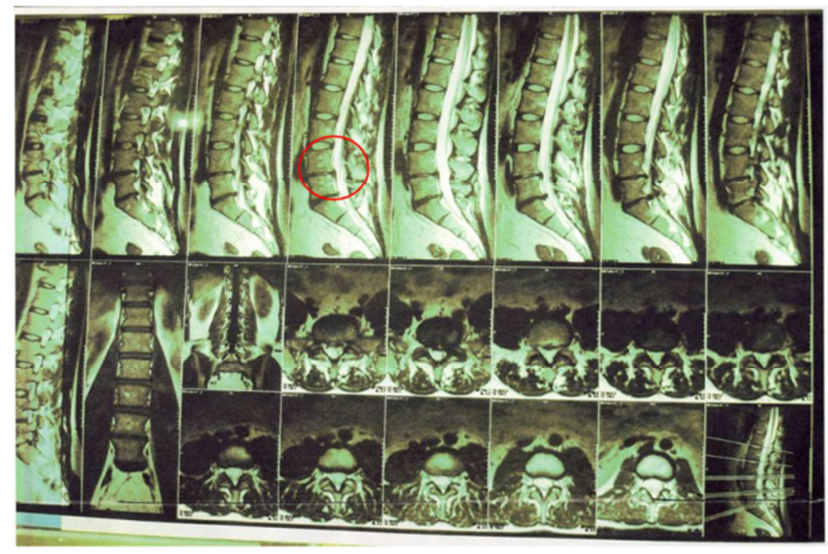

Fig. 20. Magnetic and resonant imaging of lumbosacral spine after starting the treatment. 


\section{Conclusion}

1. Carried out experiments show that water exposed to polychromatic VIP-light (Bioptron) is activated that manifests in changes of physical and chemical properties, namely, in changes of optical absorption spectra, Raman scattering and $\mathrm{pH}$ of water.

2. For water activation, time of exposure to polychromatic VIP-light is important, and any deviation from this value causes water deactivation.

3. After polychromatic VIP-light (Bioptron) exposure termination, water, both itself and in human organism, continues activating for a definite time.

4. Along with these physical and chemical manifestations, energy and information communication to the human organism was observed, proceeding, probably, via insensible water evaporation system.

5. The treatment results of patients with the spine pathology indicate the increase of physiotherapy efficiency, as combined with the medication therapy: comparing with group I of patients, treated solely by medication, regression increases by $8.4 \%$, and unchanged and aggravation states decrease by 3.7 and $4.8 \%$, respectively.

6. A significant increase of the treatment efficiency for patients from group III exposed to physiotherapy with underwater phototherapy was observed: regression $79.7 \%$, unchanged - $20.3 \%$, no aggravations, as compared with group I patients, i.e. phototherapy increases the treatment efficiency.

7. For patients treated by physiotherapy with underwater spinal traction, the efficiency is high: regression $87.1 \%$, unchanged $-12.9 \%$, no aggravations.

8. The best treatment results were observed for underwater traction combined with underwater phototherapy: regression $-97.6 \%$, unchanged $-2.4 \%$, no aggravations.

9. We assume that when in the spine pathology inflammatory processes dominate, underwater phototherapy combined with other treatment increases overall treatment efficiency. If in the spine pathology degenerative changes in the intervertebral discs prevail, the application of underwater spinal traction in combination with other methods, underwater phototherapy in particular, sharply increases efficiency and prolongs persistent remission of the disease.

\section{References}

[1] Beckij O. V., Golant M. B., Devjatkov N. D. Millimetrovye volny v biologii, Moskva, izd. "Znanie", 1988.
[2] Benujell K. "Osnovy molekuljarnoj spektroskopii. Per. s angl. - M.: Mir, 1985.

[3] Bobovich Ja. S. Poslednie dostizhenija v spektroskopii spontannogo kombinacionnogo rassejanija sveta. "Uspehi fizicheskih nauk", 1969, T. 97, vyp. 1, p. 37.

[4] Gorbunov A. M., Voloshin T. G., Il'enko V. D. Metod kontrolja struktury vody posle jenergoinformacionnoj obrabotki i ee fiziologicheskoe dejstvie. //Sbornik trudov. Mezhdunarodnyj forum "Integrativnaja medicina". M.: Medicina, 2008. - T.2 - p. 158-167.

[5] Gorbunov A. M., Voloshina T. G., Il'enko V. A. Narushenie reguljacii metabolizma belkovyh struktur - prichina vozniknovenija zabolevanij i ego korrekcija vodoj, aktivirovannoj jenergoinformacionnymi tehnologijami. //Sbornik nauchnyh trudov. III Rossijskij gameopaticheskij s\#ezd. - M.: Medicina. - 2007. - p. 242-245.

[6] Hetagurova L. G., Salbiev K. D. Hronopatofiziologija doklinicheskih narushenij zdorov'ja. Vladikavkaz, 2000, p. 146-149.

[7] Kochubej V. I., Bashkatov A. N. Spektroskopija rasseivajushhih sred. Uchebnoe posobie, Saratov, 2014g., p. 87.

[8] Monstrey. S., Hoeksema. H., Saelens. H., Depuydt. K. Hamdi. M., K. Van Landuyt and P. Blondeel KONSERVATIVNOE LEChENIE GLUBOKIH KOZhNYH OZhOGOVYH RAN S ISPOL"ZOVANIEM TERAPII POLJaRIZOVANNYM SVETOM. Britanskij zhurnal plasticheskoj hirurgii (2002) 55, 420-426.

[9] Monstrey S. Hoeksema H. Depuydt K. Van Maele G, Van Landuyt K. Blondeel P. The effect of polarized light on wound healing, Eur J Plasl Surg 2002: 24: p. 377-82.

[10] Mosin O. V. Vozdejstvie jelektromagnitnyh voln nizkoj intensivnosti na vodu i biologicheskie obekty. M., 2004.

[11] K.A. Samoilova. The mechanisms of anti-inflammatory, immunomodulatory, wound-healing and metabolism normalizing action of light from Bioptron device. // Proceedings of NEW TRENDS IN THE USE OF BIOPTRON PHOTOTHERAPY Scientific Conference. - 2003. - P. 10-14.

[12] Sinicyn N. I., Petrosjan V. I., Elkin V. A. Osobaja rol' sistemy "millimetrovye volny - vodnaja sreda" v prirode. //Biomedicinskaja radiojelektronika.//, 1998, №1, str. 5-23.

[13] V. S. Ulashchik. General Physiotherapy. - Minsk, 2005. - p. 510.

[14] Volkov E. S., Vljal'ko V. I. Jelektrichestvo na sluzhbe zdorov'ja. K.: Zdorov'e., 1989, p. 88.

[15] N. A. Zhevago, K. A. Samoilova, K. D. Obolenskaya. Cytokine content variations in peripheral blood of volunteers after exposure to polychromatic visible and infrared light. // Cytology. - 2005. - Vol. 47(5), P. 446-459. 